\title{
Levofloxacin Based H. Pylori Eradication Therapy, should we Give it A better Consideration?
}

\author{
Ahmad Nabil Lotfy Hassan* \\ Department of Tropical Medicine \& Hepatology, Faculty of Medicine, Cairo university, Egypt
}

*Corresponding author: Ahmad Nabil Lotfy Hassan, Department faculty of Medicine, Cairo University, Egypt.
Received Date: June 17, 2019

Published Date: June 19, 2019

\section{Opinion}

Helicobacter pylori (H. pylori) infection, one of the most common bacterial infections, affects approximately 50\% of the world's population [1]. H. pylori infection is a major cause of gastritis, gastric and duodenal ulcers, mucosal associated lymphoid tissue, and gastric cancer [2]. H. pylori eradication treatment has been proven to improve gastric inflammation, promote ulcer healing, and reduce the incidence of gastric cancer $[3,4]$. Furthermore, a "test-and-treat" approach is advocated for detecting and eradicating H. pylori in patients with dyspeptic symptoms but low gastric cancer risk [5].

H. pylori eradication treatment is becoming more challenging due to increasing antimicrobial resistance. Previously, a 7-d standard triple therapy consisting of a proton pump inhibitor (PPI), amoxicillin (AMPC), and clarithromycin (CAM) was recommended for eradicating H. pylori [6]. However, there has been a significant reduction in the eradication rate achieved with this regimen due to the increase in antimicrobial resistance of H. pylori. Resistance of H. pylori has reached alarming levels worldwide, which greatly affects the efficacy of treatment. The World Health Organization (WHO) published its first ever list of antimicrobial resistant "priority pathogens," which is a catalogue of 12 families of bacteria posing the greatest threat to human health. They indicated three priority statuses-critical, high, and medium-with CAM-resistant $\mathrm{H}$. pylori being categorized as a high priority bacterium in the same tier as vancomycin-resistant Enterococcus faecium and methicillinresistant Staphylococcus aureus [7].

A new strategy that can eradicate $\mathrm{H}$. pylori as well as reduce the antibiotics used is required to prevent future antimicrobial resistance in $\mathrm{H}$. pylori. Dual-therapy with vonoprazan, an oral potassium-competitive acid blocker (PCAB) and amoxicillin could be a breakthrough for H. pylori eradication in an era of growing antimicrobial resistance. This regimen may provide a satisfactory eradication rate of $\mathrm{H}$. pylori and also minimize antimicrobial resistance due to single antibiotic use and the strong inhibitory effect of vonoprazan on gastric acid secretion [8]. However, PCABs are not available outside of Asia, and data on safety and comparative efficacy with other antisecretory agents are limited [9].

Because of increasing failure of therapy, the Toronto consensus group strongly recommended that all $H$. pylori eradication regimens be given for 14 days. Recommended rescue therapies include PBMT (PPI + bismuth + metronidazole + tetracycline) and levofloxacin-containing therapy (PPI + amoxicillin + levofloxacin) [10]. Between 2002 and 2014, 110 patients in 14 medical centers received levofloxacin- based third-line $\mathrm{H}$. pylori eradication therapy for peptic ulcer disease. The overall eradiation rate was $71.6 \%$. It was concluded that Levofloxacin-based third-line $\mathrm{H}$. pylori eradication showed efficacy similar to that of previously reported first/second-line therapies [11].

Levofloxacin-containing therapy is an alternative first-line regimen [12] and consists of a PPI plus amoxicillin $1 \mathrm{~g}$ BID plus levofloxacin $500 \mathrm{mg}$ QD. 10 days (eradication rates of up to 83.1\%) [13]. 10-14 days is recommended by the 2017 American College of Gastroenterology Guidelines [14]. Sequential therapy, an alternative first-line regimen, is as follows (eradication rates of up to $86.5 \%$ ): PPI (esomeprazole $20 \mathrm{mg}$ or $40 \mathrm{mg}$ BID) plus amoxicillin (1 g BID) for 5-7 days, then PPI (esomeprazole $20 \mathrm{mg}$ or $40 \mathrm{mg}$ BID) plus levofloxacin (250 mg or $500 \mathrm{mg}$ BID) plus a nitroimidazole antibiotic (eg, tinidazole $500 \mathrm{mg}$ BID) for 5-7 days[14]. A randomized trial investigated the role of bismuth in levofloxacin-containing 14day sequential therapy and concluded that adding bismuth did not significantly improve eradication rates (85.2\% vs. $82.6 \%$ ). Concomitant therapy, another alternative first-line regimen is as 
follows (eradication rates of up to 96.5\%): PPI (esomeprazole 40 mg BID) plus amoxicillin (1 g BID) plus levofloxacin (500 mg QD) plus another antibiotic (eg, tinidazole $500 \mathrm{mg}$ BID) for 5 days [15].

Levofloxacin-based triple therapy has demonstrated efficacy as a salvage regimen in patients who have failed initial clarithromycin triple therapy or bismuth quadruple therapy. Levofloxacin triple therapy has also demonstrated efficacy in patients who have failed two prior attempts at treatment. In a pooled analysis from six European cohort studies, when used as a salvage regimen in patients who had failed two previous eradication attempts, levofloxacin triple therapy administered for 10 days has a pooled eradication rate of 73 percent [16]. Most patients in these studies were treated with clarithromycin triple therapy followed by bismuth quadruple therapy.

\section{Acknowledgement}

None.

\section{Conflict of Interest}

No conflict of interest.

\section{References}

1. Hooi JKY, Lai WY, Ng WK, Suen MMY, Underwood FE, et al. (2017) Global Prevalence of Helicobacter pylori Infection: Systematic Review and Meta-Analysis. Gastroenterology 153: 420-429.

2. Mc Coll KE (2010) Clinical practice Helicobacter pylori infection. N Engl J Med 362: 1597-1604

3. Doorakkers E, Lagergren J, Engstrand L, Brusselaers N (2018) Helicobacter pylori eradication treatment and the risk of gastric adenocarcinoma in a Western population. Gut 67: 2092-2096.

4. Choi IJ, Kook MC, Kim YI, Cho SJ, Lee JY, et al. (2018) Helicobacter pylori Therapy for the Prevention of Metachronous Gastric Cancer. N Engl J Med 378: 1085-1095.

5. Malfertheiner P, Megraud F, O Morain CA, Gisbert JP, Kuipers EJ, et al (2017) Management of Helicobacter pylori infection-the Maastricht V/ Florence Consensus Report. Gut 66: 6-30.
6. Malfertheiner P, Megraud F, O Morain C, Bazzoli F, El-Omar E, et al. (2017) Current concepts in the management of Helicobacter pylori infection: the Maastricht III Consensus Report. Gut 56: 772-781.

7. Savoldi A, Carrara E, Graham DY, Conti M, Tacconelli E, et al. (2018) Prevalence of Antibiotic Resistance in Helicobacter pylori: A Systematic Review and Meta- analysis in World Health Organization Regions. Gastroenterology 155: 1372-1382.e17.

8. Sho Suzuki, Mitsuru Esaki, Chika Kusano, Hisatomo Ikehara, Takuji Gotoda (2019) Development of Helicobacter pylori treatment: How do we manage antimicrobial resistance? World J Gastroenterol 25(16): 1907-1912.

9. Murakami K, Sakurai Y, Shiino M, Funao N, Nishimura A, et al. (2016) Vonoprazan, a novel potassium- competitive acid blocker, as a component of first line and second-line triple therapy for Helicobacter pylori eradication: a phase III, randomised, double-blind study. Gut 65: 1439-1446.

10. Fallone CA, Chiba N, Van Zanten SV, Fischbach L, Gisbert JP, et al. (2016) The Toronto Consensus for the Treatment of Helicobacter pylori Infection in Adults. Gastroenterology 151(1): 51-69. e14.

11. Lim JH, Kim SG, Song JH, Hwang JJ, Lee DH, et al. (2017) Efficacy of Levofloxacin-Based Third-Line Therapy for the Eradication of Helicobacter pylori in Peptic Ulcer Disease. Gut Liver 11(2): 226-231.

12. Shah A, Javid G, Zargar SA, Teli F, Khan BA, et al. (2013) Safety and efficacy of 1-week levofloxacin-based triple therapy in first-line treatment for Helicobacter pylori-related peptic ulcer disease in Kashmir, India. Indian J Gastroenterol 32(1): 32-36.

13. Chey WD, Wong BC (2017) American College of Gastroenterology guideline on the management of Helicobacter pylori infection. Am J Gastroenterol 102(8): 1808-1825.

14. Chey WD, Leontiadis GI, Howden CW, Moss SF (2017) ACG Clinical Guideline: Treatment of Helicobacter pylori Infection. Am J Gastroenterol 112 (2): 212-239.

15. Federico A, Nardone G, Gravina AG, Iovene MR, Miranda A, et al. (2012) Efficacy of 5-day levofloxacin-containing concomitant therapy in eradication of Helicobacter pylori infection. Gastroenterology 143(1): 55-61. e1.

16. Gisbert JP (2012) Letter: third-line rescue therapy with levofloxacin after failure of two treatments to eradicate Helicobacter pylori infection. Aliment Pharmacol Ther 35: 1484-1485. 